\title{
Checking presence of excess volatility in forecasting volatility of a set of market indexes through an empirical comparison of three GARCH models
}

Islem Boutabba,

Department of Management, IHEC, University of Carthage, Tunisia.

\section{ABSTRACT}

islemboutabba@hotmail.com

Classical financial theory is based on Efficient Market Hypothesis (EMH). Several researchers like 'Schiller (1981) (1990), Le Roy and Porter (1980) have extensively argued for the invalidity of EMH.

Volatility excess has been detected and highlighted by many researchers; however it has not been explained very well by $\mathrm{EMH}$.

For this reason, we conducted an empirical study to identify the variable characteristics of volatility by comparing three $\mathrm{GARCH}$ models (GARCH, E-GARCH and GRJ-GARCH) over five different market indexes to examine prediction of returns volatility.

This comparison led us to detect several volatility characteristics like volatility clustering and leverage effect. This change in volatility regime is an irrefutable proof of the presence of volatility excess.

Given the inability of classical financial theory in explaining volatility excess, researchers started to focus on behavioural finance (Barret and Saphister (1996)).

\section{Indexing terms/Keywords}

volatility, Volatility excess, GARCH models;

\section{Academic Discipline And Sub-Disciplines}

Finance, Classical finance;

\section{SUBJECT CLASSIFICATION}

Financial subject classification

\section{TYPE (METHOD/APPROACH)}

Quantitative approach (Econometry).

\section{Council for Innovative Research}

\author{
Peer Review Research Publishing System
}

\section{Journal: JOURNAL OF SOCIAL SCIENCE RESEARCH}

Vol 4, No 2

jssreditor.cir@gmail.com

www.jssronline.com/ojs 


\section{INTRODUCTION}

Since the 1987 stock market crash, modeling and forecasting the financial markets volatility has received a significant attention from academics and practitioners because of its central position in many financial applications: assets valuation, allocation of wealth and hedging against risk.

In addition, the financial world has witnessed the bankruptcy or pre-bankruptcy of several institutions that have incurred great losses because of their exposure to impromptu market movements for over a decade. These financial disasters highlighted more the significance of predicting volatility in risk management. Given these facts, the quest for accurate forecasts still appear in progress.

While it is admitted that volatility is often marked by a number of stylized facts, such as persistence, volatility clustering, time-varying volatility and leptokurtic data behaviour, the introduction of the GARCH model developed by Engle (1982) and Bollerslev (1986), has created a new approach useful to recommend these time dependencies to financial econometricians. It has become a popular tool for modeling and forecasting volatility.

However, despite success of the GARCH model, it has been marked by a failure to capture asymmetric volatility ${ }^{1}$. This limitation has been overcome by introducing more flexible treatment of volatility through recommending asymmetric responses of volatility to positive and negative shocks.

This new class of asymmetric GARCH models include exponential GARCH (EGARCH) of Nelson (1991) and threshold $\mathrm{GARCH}^{2}$ (GJR-GARCH) of Glosten, Jagannathan and Runkle (1993). In this section, we compare the predictive power of volatility for these three models over 5 markets.

\section{1 - PRESENTATION OF THE THREE GARCH MODELS:}

Let $r_{t}=100 \times\left(\ln P_{t}-\ln P_{t-1}\right)$ which denotes the continuous composite returns rate in period $t-1$ to t, where $P_{t}$ is the level of asset prices at date $t$. $\Omega_{t-1}$ denotes the set of all information of observed returns up to $t-1$.

\section{1-1 - GARCH-type Predictive Models of Volatility:}

A symmetric GARCH $(1,1)$ model with a basic mean can be formulated as follows:

$r_{t}=\mu+\varepsilon_{t}, \varepsilon_{t}=\sigma_{t} z_{t},\left.\quad z_{t}\right|_{\Omega_{t-1}} \sim F(0,1)$ et i.i.d

$\sigma_{t}^{2}=\omega+\alpha \varepsilon_{t-1}^{2}+\beta \sigma_{t-1}^{2}$

Where $\mu$ and $\mu$ and $\sigma_{t}^{2}$ denote respectively conditional mean and variance of returns. $\varepsilon_{t}$ is the innovation process, while $F(0,1)$ is the density function with a zero mean and variance equal to unity. In addition, $\omega, \alpha$ and $\beta$ are non-negative parameters with an $\alpha+\beta<1$ restriction to ensure positivity of conditional variance and stationarity.

Two simple classes of models, which may cope with asymmetric volatility in response to asymmetric shocks, are the GJRGARCH model proposed by Glosten et al. (1993) and the exponential GARCH (EGARCH) model advocated by Nelson (1991). The GJR-GARCH model differs from the (2) model as follows:

$\sigma_{t}^{2}=\omega+\alpha \varepsilon_{t-1}^{2}+\delta I_{t-1} \varepsilon_{t-1}^{2}+\beta \sigma_{t-1}^{2}$

Where the $I_{t-1}$ dummy function takes the value of unity if $\varepsilon_{t}<0$ and zero otherwise. The dummy variable distinguishes between positive and negative shocks, in a way that asymmetric effects in data will be captured by $\delta$.

Thus, in GJR-GARCH, positive information has an impact $\alpha$ and negative information has an impact $\alpha+\delta$, with the fact that negative (positive) information has a greater effect on volatility if $\delta>0(\delta<0)$.. In addition, $\omega, \alpha$ et $\beta$ are non-negative parameters with a $\alpha+\beta+0,5 \delta<1$ restriction, therefore estimating the sum $\alpha+0,5 \delta$ should still be positive (Ling and McAleer (2002)).

The EGARCH model of Nelson (1991) provides an alternative asymmetric model in the following lines:

$\log \left(\sigma_{t}^{2}\right)=\omega+\alpha\left[\gamma \frac{\varepsilon_{t-1}}{\sigma_{t-1}}+\left|\frac{\varepsilon_{t-1}}{\sigma_{t-1}}\right|-\sqrt{2 / \pi}\right]+\beta \log \left(\sigma_{t-1}^{2}\right)$

Where the coefficient $y$ captures the asymmetric impact of information with the fact that negative shocks have a greater impact than similar positive shocks if $\gamma<0$.. The effect of clustering is captured by a significant $\alpha$ coefficient. Finally, the use of the logarithmic form allows parameters to be negative without conditional variance becoming so.

\footnotetext{
${ }^{1}$ For assets prices, negative shocks (bad news) have generally a higher impact on volatility than positive shocks (good news). This phenomenon is also known as leverage effect.

${ }^{2}$ Threshold GARCH.
} 


\section{1-2 - Distribution Hypotheses:}

Another finding in the GARCH literature is the abnormal characteristics of distribution of financial returns. To model such a phenomenon when estimating a GARCH model, Theodossiou (1998) forewarned a $\mathrm{SGT}^{3}$ distribution that constitutes a flexible tool for modeling distribution of financial data which exhibits fat tails, leptokurtic shapes and asymmetry (skewness).

Probability density function of SGT $\left(\mathrm{pdf}^{4}\right)$ for standardized residuals $\left(z \_t\right)$ of returns can be defined as follows:

$F\left(z_{t} ; N, k, \lambda\right)=C\left(1+\frac{\left|z_{t}+\delta\right|^{k}}{((N+1) / k)\left(1+\operatorname{sign}\left(z_{t}+\delta\right) \lambda\right)^{k} O^{k}}\right)^{-(N+1) / k}$

Where :

$C=0,5 k \times\left(\frac{N+1}{k}\right)^{-1 / k} \times B\left(\frac{N}{K}, \frac{1}{K}\right)^{-1} \times O^{-1}$

$O=\left(g-\rho^{2}\right)^{-1 / 2}$

$\rho=2 \lambda \times B\left(\frac{N}{K}, \frac{1}{K}\right)^{-1} \times\left(\frac{N+1}{k}\right)^{-1 / k} \times B\left(\frac{N-1}{k}, \frac{2}{k}\right)$

$g=\left(1+3 \lambda^{2}\right) \times B\left(\frac{N}{K}, \frac{1}{K}\right)^{-1} \times\left(\frac{N+1}{k}\right)^{-1 / k} \times B\left(\frac{N-2}{k}, \frac{3}{k}\right)$

$\delta=\rho \times O$

Where $z_{t}$ is standardized residual with a zero mean and a variance equal to unity, $N$ is the tail thickness parameter ${ }^{5}$ with a $N>2$ constraint, $k$ is a leptokurtic parameter with $k>0 ; \lambda$ governs density skewness under the $|\lambda|<1$ constraint, sign is the sign function and $B($.$) denotes the beta function. (.) In particular, the SGT distribution characterizes several well-$ known distributions. More specifically, for $k=2$ et $\lambda=0$ it gives a t-student distribution and for $N=\infty, k=2$ et $\lambda=0$ it gives the normal distribution.

However, several recent papers have reported more new findings for heavy-tailed distributions $(\mathrm{HT})^{6}$, like Politis (2004) and Hung et al. (2008). With a HT distribution, probability density function of innovations becomes:

$F\left(z_{t}, a_{0}, 1\right)=\frac{\left(1+a_{0} z_{t}^{2}\right)^{-1,5} \exp \left(\frac{z_{t}^{2}}{2\left(1+a_{0} z_{t}^{2}\right)}\right)}{\sqrt{2 \pi}\left(\phi\left(a_{0}^{-0,5}\right)-\phi\left(-a_{0}^{-0,5}\right)\right)}$

Where 1 denotes the standard deviation of $z_{t}$ and $\phi$ denotes the cumulative probability density function of the standard normal distribution. The Sharpe parameter, $a_{0}$, reflects the degree of heavy tails with the $O<a_{0}<1$. constraint. When $a_{0} \rightarrow 0$, HT will be reduced to a standard normal distribution, while the distribution have denser tails than the normal distribution when $a_{0} \rightarrow 1$ (or Politis (2004)).

In our study, we make recourse to three model specifications to model GARCH, GJR-GARCH and EGARCH volatility.

\section{2 - HYPOTHESES AND DATA:}

Our empirical specification will aim at testing the following hypotheses:

- Hypothesis 1: Volatility of markets index returns has different regimes; therefore there is volatility excess;

- Hypothesis 2: Volatility of markets index returns follows a single regime; therefore there is no volatility excess.

To test our hypotheses, we will compare the predictive power of the three asymmetric volatility models of GARCH, GJRGARCH and EGARCH. This procedure is done on 5 markets, notably BVSP (Brazil), MERV (Argentina), MXX (Mexico), HSI (China) and GDAXI (Germany).

We will use daily prices of these indexes over the period stretching from $18^{\text {th }}$ January 2002 to $31^{\text {st }}$ December 2012 , a total of 2709 days. The prices were taken from the Yahoo Finance database.

\section{3- THE RESULTS AND THEIR INTERPRETATIONS:}

\section{3-1- Descriptive Statistics of Time-series}

\footnotetext{
${ }^{3}$ Skewed Generalized t.: biased generalized t statistic.

${ }^{4}$ Probability density function

${ }^{5}$ Tail-thickness parameter

${ }^{6}$ Heavy-tailed distribution
} 
Table 1 reports the characteristics of the returns of the chosen five market indexes:

Table 1. Descriptive statistics of the five markets returns

\begin{tabular}{|l|c|c|c|c|c|}
\hline \multicolumn{1}{|c|}{ Statistics } & BVSP & GDAXI & HSI & MERV & MXX \\
\hline Mean & 0,0225205 & 0,000371 & 0,004473 & 0,0297005 & 0,0267008 \\
\hline Maximum & 5,939677 & 4,68928 & 5,822503 & 6,999315 & 4,534343 \\
\hline Minimum & $-5,253248$ & $-3,228312$ & $-5,898598$ & $-5,624822$ & $-3,590464$ \\
\hline Skewness & $-0,08614$ & 0,0648492 & $-0,0454581$ & $-0,0771208$ & 0,0450354 \\
\hline Kurtosis & 6,551229 & 7,213832 & 10,76151 & 7,851749 & 7,124008 \\
\hline Median & 0,0524867 & 0,031519 & 0,139656 & 0,0475758 & 0,0528936 \\
\hline Stand. Dev & 0,8575317 & 0,7091557 & 0,7221079 & 0,9557759 & 0,6507112 \\
\hline Normality test ${ }^{\prime}(\mathrm{W})$ & & & & & 0,93922 \\
& 0,96829 & 0,94828 & 0,92495 & $-49,700$ & $-47,119$ \\
\hline ADF Test & $-51,753$ & $-54,079$ & $-53,418$ & 0,114 & 0,116 \\
\hline KPSS Test $^{8}$ & 0,229 & 0,107 & 0,0727 & 0 & 0,00001 \\
\hline LM $^{9}$ Test & 0,00615 & 0,40295 & 0,89698 & & 0,94959 \\
\hline
\end{tabular}

This table shows us that the returns of the five markets are differently distributed. We notice divergent means. They vary between 0,000371 (GDAXI) and 0,0297005 (MERV). However, maximum values range between 4,534343 (MXX) and 6,999315 (MERV). The minimum values are all negative and vary between $-5,898598$ (HSI) and $-3,228312$ (GDAXI).

We found two types of distributions; GDAXI and MXX have tails skewed to the right and distributions skewed to the left. The other indexes have distributions skewed to the right and tails skewed to the left. Kurtosis coefficients are superior to 3 , therefore the 5 markets returns distributions are leptokurtic.

Shapiro-Wilk normality test reported null $p$-values and consequently, daily returns of the five markets are not normally distributed. Dickey-Fuller Augmented test reported negative values inferior to the critical values corresponding to the number of observations, then the null hypothesis which assumes presence of a unit root is rejected.

However, the KPSS test indicates that the null hypothesis of the presence of stationarity is rejected for all markets except for BVSP for which stationarity hypothesis is accepted even at the $1 \%$ level. Finally, Lagrange-Multiplier test indicates that only GDAXI and HSI present errors autocorrelations.

Ces analyses préliminaires des données encouragent l'adoption, d'une part, des distributions sophistiquées ayant des queues épaisses, et d'autre part, des modèles conditionnels qui permettent des volatilités qui varient dans le temps.

\section{3-2- The Results and Their Interpretations:}

To compare the three GARCH models, first we should look into their overall significance. Table 2 reports the results of the Wald $\mathrm{Chi}^{2}$ test:

Table 2. the overall significance of the three models through the Wald $\mathrm{Chi}^{2}$ test $^{2}$

\begin{tabular}{|l|c|c|c|c|c|c|}
\hline \multirow{2}{*}{\multicolumn{1}{c|}{ Indexes }} & \multicolumn{2}{c|}{ GARCH } & \multicolumn{2}{c|}{ EGARCH } & \multicolumn{2}{c|}{ GJR-GARCH } \\
\cline { 2 - 7 } \multicolumn{1}{c|}{ Statistic } & P-value & Statistic & P-value & Statistic & P-value \\
\hline BVSP & 10,63 & 0,0011 & 10,24 & 0,0014 & 10,46 & 0,0012 \\
\hline GDAXI & 4,46 & 0,0347 & 8,51 & 0,0035 & 5,55 & 0,0184 \\
\hline HSI & 22,36 & 0 & 17,90 & 0 & 27,42 & 0 \\
\hline MERV & 18,85 & 0 & 18,38 & 0 & 22,59 & 0 \\
\hline
\end{tabular}

\footnotetext{
${ }^{7}$ Shapiro-Wilk normality test, if $\mathrm{p}$-value $<0$, then the null hypothesis is rejected. Therefore, data is not normally distributed.

${ }^{8}$ Stationarity test of Kwiatkowski-Phillips-Schmidt-Shin.

${ }^{9}$ Lagrange-Multiplier test of auto-correlation of returns.
} 


\begin{tabular}{|l|c|c|c|c|c|c|}
\hline MXX & 15,15 & 0,0001 & 16,05 & 0,0001 & 18,13 & 0 \\
\hline
\end{tabular}

The Wald $\mathrm{Chi}^{2}$ test indicates that the three models are overall significant at the $5 \%$ level. Nevertheless, accepting the overall significance hypothesis may done at the $1 \%$ level for the three models and only for four markets (BVSP, HSI, MERV and MXX), and only for the EGARCH model for GDAXI. Indeed, the p-values are inferior to $1 \%$ for 16 of the 18 conducted regressions.

Overall significance may be better tested by the log-likelihood ratio test. This latter is articulated around one hypothesis, i.e. the distribution takes a $\mathrm{Chi}^{2}$ distribution. The Wald $\mathrm{Chi}^{2}$ test has an additional hypothesis, which knowing in advance standard error. Table 3 reports the results of the log-likelihood test.

Table 3. overall significance through the log-likelihood ratio test

\begin{tabular}{|l|c|c|c|}
\hline \multicolumn{1}{|c|}{ Indexes } & GARCH & EGARCH & GJR-GARCH \\
\hline BVSP & $-3430,314$ & $-3427,400$ & $-3428,453$ \\
\hline GDAXI & $-2819,362$ & $-2845,994$ & $-2818,297$ \\
\hline HSI & $-2806,589$ & $-2842,037$ & $-2801,311$ \\
\hline MERV & $-3591,131$ & $-3621,846$ & $-3589,307$ \\
\hline MXX & $-2551,024$ & $-2572,759$ & $-2549,473$ \\
\hline
\end{tabular}

The log-likelihood statistics are negative and low, and therefore we may conclude that the three models are overall significant for the five markets.

As a second step, we will examine individual significance of each model's parameters for each market. Table 4 reports the results:

Table 4. Individual significance of regressions parameters

\begin{tabular}{|c|c|c|c|c|c|c|c|c|c|c|c|}
\hline \multirow[b]{2}{*}{ Model } & \multirow[b]{2}{*}{$\begin{array}{c}\text { Parameter } \\
\mathbf{s}\end{array}$} & \multicolumn{2}{|c|}{ BVSP } & \multicolumn{2}{|c|}{ GDAX } & \multicolumn{2}{|c|}{ HSI } & \multicolumn{2}{|c|}{ MERV } & \multicolumn{2}{|c|}{ MXX } \\
\hline & & $\begin{array}{c}\text { Statisti } \\
\text { C }\end{array}$ & $\begin{array}{c}\text { P. } \\
\text { valu } \\
\text { e }\end{array}$ & $\begin{array}{c}\text { Statisti } \\
\text { C }\end{array}$ & $\begin{array}{c}\text { P- } \\
\text { valu } \\
\text { e }\end{array}$ & $\begin{array}{c}\text { Statisti } \\
\text { c }\end{array}$ & $\begin{array}{c}\text { P. } \\
\text { valu } \\
\text { e }\end{array}$ & $\begin{array}{c}\text { Statisti } \\
\text { C }\end{array}$ & $\begin{array}{c}\text { P- } \\
\text { valu } \\
\text { e }\end{array}$ & $\begin{array}{c}\text { Statistiqu } \\
\text { e }\end{array}$ & $\begin{array}{c}\text { P- } \\
\text { valu } \\
\text { e }\end{array}$ \\
\hline \multirow[t]{3}{*}{ GARCH } & $M C^{10}$ & 3,26 & $\begin{array}{c}0,00 \\
1\end{array}$ & 2,11 & $\begin{array}{c}0,03 \\
5\end{array}$ & 4,73 & $\begin{array}{c}0,00 \\
0\end{array}$ & 4,34 & $\begin{array}{c}0,00 \\
0\end{array}$ & 3,89 & $\begin{array}{c}0,00 \\
0\end{array}$ \\
\hline & $\mathrm{L}^{11} \mathrm{ARCH}$ & $-0,68$ & $\begin{array}{c}0,49 \\
7\end{array}$ & 12,23 & $\begin{array}{c}0,00 \\
0\end{array}$ & 14,67 & $\begin{array}{c}0,00 \\
0\end{array}$ & 12,27 & $\begin{array}{c}0,00 \\
0\end{array}$ & 12,68 & $\begin{array}{c}0,00 \\
0\end{array}$ \\
\hline & $\begin{array}{l}\text { Cons }^{12} \\
\text { ARCH }\end{array}$ & 59,75 & $\begin{array}{c}0,00 \\
0\end{array}$ & 55,06 & $\begin{array}{c}0,00 \\
0\end{array}$ & 50,40 & $\begin{array}{c}0,00 \\
0\end{array}$ & 48,36 & $\begin{array}{c}0,00 \\
0\end{array}$ & 50,20 & $\begin{array}{c}0,00 \\
0\end{array}$ \\
\hline \multirow[t]{4}{*}{$\begin{array}{l}\text { EGARC } \\
\mathrm{H}\end{array}$} & $\mathrm{MC}$ & 3,20 & $\begin{array}{c}0,00 \\
1\end{array}$ & 2,92 & $\begin{array}{c}0,00 \\
4\end{array}$ & 4,23 & $\begin{array}{c}0,00 \\
0\end{array}$ & 4,29 & $\begin{array}{c}0,00 \\
0\end{array}$ & 4,01 & $\begin{array}{c}0,00 \\
0\end{array}$ \\
\hline & $\begin{array}{l}\mathrm{L} 1 \\
\mathrm{EARCH}^{13}\end{array}$ & 1,41 & $\begin{array}{c}0,15 \\
9\end{array}$ & 2,10 & $\begin{array}{c}0,03 \\
6\end{array}$ & 4,40 & $\begin{array}{c}0,00 \\
0\end{array}$ & 1,45 & $\begin{array}{c}0,14 \\
6\end{array}$ & 0,89 & $\begin{array}{c}0,37 \\
3\end{array}$ \\
\hline & $\begin{array}{l}\text { L1 } \\
\text { EARCH- } \\
A^{14}\end{array}$ & $-3,45$ & $\begin{array}{c}0,00 \\
1\end{array}$ & 10,01 & $\begin{array}{c}0,00 \\
0\end{array}$ & 13,77 & $\begin{array}{c}0,00 \\
0\end{array}$ & 15,29 & $\begin{array}{c}0,00 \\
0\end{array}$ & 13,81 & $\begin{array}{c}0,00 \\
0\end{array}$ \\
\hline & $\begin{array}{l}\text { Con } \\
\text { EARCH- } \\
A^{15}\end{array}$ & $-19,27$ & $\begin{array}{c}0,00 \\
0\end{array}$ & $-37,94$ & $\begin{array}{c}0,00 \\
0\end{array}$ & $-44,27$ & $\begin{array}{c}0,00 \\
0\end{array}$ & $-7,02$ & $\begin{array}{c}0,00 \\
0\end{array}$ & $-47,04$ & $\begin{array}{c}0,00 \\
0\end{array}$ \\
\hline $\begin{array}{l}\text { GJR- } \\
\text { GARCH }\end{array}$ & $\mathrm{MC}$ & 3,23 & $\begin{array}{c}0,00 \\
1\end{array}$ & 2,36 & $\begin{array}{c}0,01 \\
8\end{array}$ & 5,24 & $\begin{array}{c}0,00 \\
0\end{array}$ & 4,75 & $\begin{array}{c}0,00 \\
0\end{array}$ & 4,26 & $\begin{array}{c}0,00 \\
0\end{array}$ \\
\hline
\end{tabular}

\footnotetext{
${ }^{10}$ Conditional mean

${ }^{11}$ First lag of GARCH.

${ }^{12}$ Constant of GARCH.

${ }^{13}$ First lag of EARCH.

${ }^{14}$ First lag of EARCH-A.

${ }^{15}$ Constant of EARCH-A.
} 


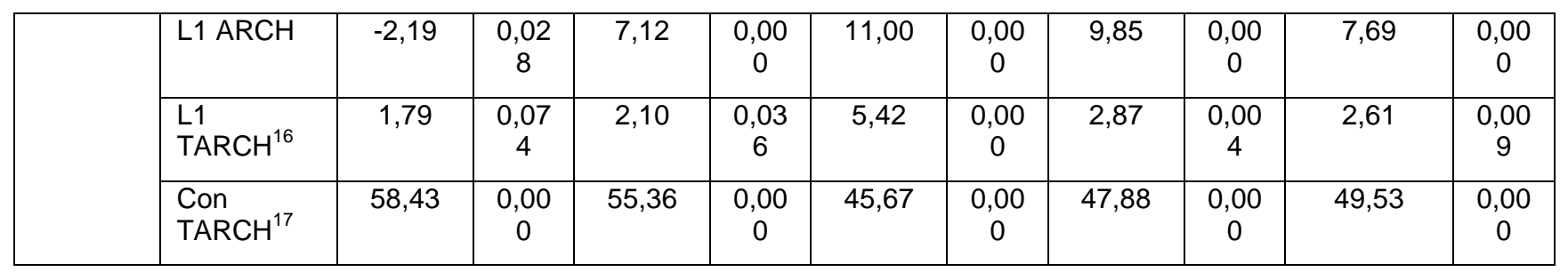

The table above first indicates that the components of GARCH are significant at the $1 \%$ level for all markets except for BVSP. The L1 parameter is non-significant for Brazil ( $p$-value $>5 \%$ ). Conditional mean is significant at the $1 \%$ level for the four markets: BVSP, HSI, MERV and MXX and at the 5\% level for GDAX.

Concerning EGARCH, we found that conditional mean is significant at the $1 \%$ level for the five markets. The same is true for L1 parameter and the constant Con EARCH-A. Nevertheless, these three markets do not present errors autocorrelation. Therefore, EGARCH explains very well volatility of the markets with auto-correlated errors, notably GDAXI and HSI.

GJR-GARCH parameters are all significant at the \% level for HSI, MERV and MXX, whereas for GDAX, MC and L1 TARCH are significant at the $5 \%$ level. As for BVSP, L1 TARCH is not significant and it is only significant at the $5 \%$ level. BVSP is marked by stationarity of returns.

In summary, GARCH models explained very well volatility of HSI, MERV, MXX and GDAX. The simplest GARCH family model could not function for VSP because the KPSS test showed stationarity of its returns. We may conclude that volatility of returns of HSI, MERV, MXX and GDAX presents symmetry of responses to positive and negative market information.

The EGARCH model explained very well volatility of returns only for GDAX. We may deduce that this model is not adequate. This model differs from the GARCH model by the fact that it efficiently captures volatility clustering and leverage effects. Since GDAX has been very well explained by $\mathrm{GARCH}$, therefore volatility does not present a leverage effect of negative information against positive information. EGARCH highlighted clustering of volatility of returns for this index.

Volatility clustering is defined by Mandelbrot (1963) as "substantial changes followed by other substantial changes of whatever sign and small changes are followed by small changes". A quantitative illustration of this fact is that when returns are not auto-correlated, absolute returns $\left(\left|r_{t}\right|\right)$ show a significant auto-correlation function and start slowly to disappear.

The GARCG model is marked, on the one hand, by uncorrelated serial error processes $\left(u_{t}\right)$ with a zero mean, and on the other hand by a symmetric response of current volatility to positive or negative lagged errors $\left(u_{t-1}\right)$. However, since error $u_{t}$ is not correlated to its past, it may be considered as a measure of new information entering the financial market at moment t. Consequently, negative information will have a typically higher impact on future volatility of returns than positive information.

Such asymmetry of responses to market information is called leverage effect. It cannot be captured by a basic GARCH model. The EGARCH model is an exponential extension of the GARCH model. Volatility is measured by conditional variance. It is considered as a multiplying function of lagged innovations by opposition to the GARCH model which is an additional function of lagged error terms. Consequently, variance becomes very sensitive to the model's parameters.

The GRJ-GARCH allows for having different impacts of positive and negative lagged innovations. It allows for detecting the leverage effect. The GRJ-GARCH model showed performance similar to that of the GARCH model. Absence of a unit root, non-normality of returns and their leptokurtic distributions has contributed to such a result. The GRJ-GARCH is more sophisticated than the EGARCH model. It allows the leverage effect for positive and negative variations. It shows therefore more acceptable performance in explaining volatility of the five markets. Then, we accept the first hypothesis which assumes that volatility of returns has different regimes, thus there is volatility excess. This excess is illustrated by changing volatility regimes captured by these three models: volatility clustering and leverage effect. This result corroborates that of Blitz, Pang, Van Vliet (2012) and Conrad and Loch (2012).

Comparing performance of the GARCH-type models in explaining volatility of returns of the five markets points to the insufficiency of the EGARCH model compared to GARCH and GJR-GARCH models because of errors terms characteristics. However, we were able to study the performance of other models belonging to the same family, mainly GARCH-N, GARCH-t, GARCH-HT, etc. Detecting volatility characteristics (leverage and clustering effects) leads us to check for presence of volatility excess, thus checking our first hypothesis.

Moreover, we could use the SPA ${ }^{18}$ test, proposed by Hansen (2005), which is a robust and a more accurate test. It examines the relative performance of $\mathrm{GARCH}$-type models aimed at studying symmetric or asymmetric distributions. This test requires inter-daily data (5,15 and 60 minutes) unavailable in this study.

Volatility is a fundamental variable in theory and practice. Its central role is to evaluate assets and manage risk. Since true volatility cannot be observed, we chose variance as a proxy. It is computed through sums of squared inter-daily returns.

\footnotetext{
16 First lag of TARCH.

17 Constant of TARCH.

${ }^{18}$ Superior Predictive Ability test
} 
Nevertheless, the precision of this estimator is affected by market microstructure noise, especially when data is highfrequency data.

\section{ACKNOWLEDGMENTS}

Our thanks to all the people who have contributed towards development of this work.

\section{REFERENCES}

[1] Blaga, L, 2012. "Testing the financial market informational efficiency in emerging states",Review of Applied Socioeconomic Research Vol.4, Issue 2, p 181.

[2] Blitz, D., Pang, J. and Van Vliet, P., 2012.“The Volatility Effect in Emerging Markets”, Social Science Research Network, available on SSRN: http://ssrn.com/abstract=2050863.

[3] Bollerslev, T., (1986), " Generalized Autoregressive Conditional Heteroscedasticity", Journal of Econometrics, Vol.31, pp.307-327.

[4] Conrad, C. and Loch, K., 2012."Anticipating Long-Term Stock Market Volatility", University of Heidelberg, Department of Economics, Discussion Paper No. 535.

[5] Engle, R., (1982), "Autoregressive Conditional Heteroscedasticity with estimates of the variance of United Kingdom inflations", Econometrica, Vol.50, pp.987-1008.

[6] Glosten, L., Jagannathan, R. and Runkle, D., «On the Relation between the Expected Value and the Volatility Nominal Excess Return on Stocks », Journal of Finance, 46, 1779-1801, 1993.

[7] Ling, S. and MacAleer, M., "Stationarity and the Existence of Moments of Family of GARCH Processes ", Journal of Econometrics, 106, 109-117, 2002.

[8] Mandelbrot, B., (1963), "The variation of certain speculative prices", Journal of Business, Vol.36, pp.394-419.

[9] Theodossiou, P., «Financial Data and the Skewed Generalized t Distribution », Management Science, 44, 1650$1661,1998$.

\section{Author' biography with Photo}

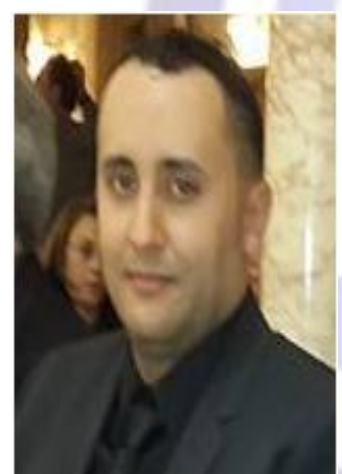

Name \& surname

Islem BOUTABBA

Address $\quad: 3$ rue des Ecoles La Goulette, Tunisia

Telephone : :21698203744

E-mail :islemboutabba@hotmail.com

Date of birth $\quad$ :5 March 1980

Nationality :Tunisian

Sex : Male

Marital status : Single

\section{Education/Qualifications}

2007-2008 University of Carthage, IHEC, Masters in Finance, currency and banks.

2004-2005 University of Sousse, ISG, Mastery in finance.

\section{Employment to Date/Work Experience}

2008-present University teacher in ESC, University of Manouba.

2007-2008 Backoffice treasurer in ABC bank. 